\title{
Power Quality in Grid connected Renewable Energy Systems: Role of Custom Power Devices
}

\author{
S. K. Khadem, M. Basu and M.F. Conlon \\ Electric Power Research Group, \\ School of Electrical Engineering Systems, Dublin Institute of Technology \\ Kevin Street, Dublin 8, Ireland \\ Phone: +35314022814, Email: skkhadem@gmail.com, mbasu@ieee.org, michael.conlon@dit.ie
}

\begin{abstract}
This paper presents a technical review of power quality problems associated with the renewable based distributed generation systems and how custom power devices (CPD) such as STATCOM, DVR and UPQC play an important role in power quality improvement. IEEE and IEC standards for grid connected renewable energy systems are one of the critical points of interest for the selection of custom power devices. PV and wind energy systems integration issues and associated PQ problems are discussed. The role of CPDs in enhancing the integration of renewables and providing quality power through custom power park are described.
\end{abstract}

\section{Keywords}

Renewable Energy Systems, Grid Integration, Power Quality, Custom Power Devices, Distributed Generation, Custom Power Park.

\section{Introduction}

Centralized power generation systems are facing the twin constraints of shortage of fossil fuel and the need to reduce emissions. Long transmission lines are one of the main causes for electrical power losses. Therefore, emphasis has increased on distributed generation (DG) networks with integration of renewable energy systems into the grid, which lead to energy efficiency and reduction in emissions. With the increase of the renewable energy penetration to the grid, power quality (PQ) of the medium to low voltage power transmission system is becoming a major area of interest. Most of the integration of renewable energy systems to the grid takes place with the aid of power electronics converters. The main purpose of the power electronic converters is to integrate the DG to the grid in compliance with power quality standards. However, high frequency switching of inverters can inject additional harmonics to the systems, creating major PQ problems if not implemented properly.

Custom Power Devices (CPD) like STATCOM (Shunt Active Power Filter), DVR (Series Active Power Filter) and UPQC (Combination of series and shunt Active Power Filter) are the latest development of interfacing devices between distribution supply (grid) and consumer appliances to overcome voltage/current disturbances and improve the power quality by compensating the reactive and harmonic power generated or absorbed by the load.

Solar and wind are the most promising DG sources and their penetration level to the grid is also on the rise. Although the benefits of DG includes voltage support, diversification of power sources, reduction in transmission and distribution losses and improved reliability [1], power quality problems are also of growing concern. This paper deals with a technical survey on the research and development of PQ problems related to solar and wind energy integrated to the grid and the impact of poor PQ. The probable connection topologies of CPDs into the system to overcome the PQ problems are also discussed. A custom power park concept for the future grid connection of distributed generation system is mentioned.

\section{Power Quality Issues (DG)}

Approximately 70 to $80 \%$ of all power quality related problems can be attributed to faulty connections and/or wiring [2]. Power frequency disturbances, electromagnetic interference, transients, harmonics and low power factor are the other categories of PQ problems (shown in Table 1) that are related to the source of supply and types of load [3].

Among these events, harmonics are the most dominant one. The effects of harmonics on PQ are specially described in [4]. According to the IEEE standard, harmonics in the power system should be limited by two different methods; one is the limit of harmonic current that a user can inject into the utility system at the point of common coupling (PCC) and the other is the limit of harmonic voltage that the utility can supply to any customer at the PCC. Details of these limits can be found in [5]. Again, DG interconnection standards are to be followed considering $\mathrm{PQ}$, protection and stability issues [6]. 
Table 1 - Categories of PQ Problems

\begin{tabular}{|c|c|c|c|c|c|}
\hline $\begin{array}{l}\text { Power Freq } \\
\text { Disturbance }\end{array}$ & $\begin{array}{l}\text { Electro Magnetic } \\
\text { Interferences }\end{array}$ & $\begin{array}{l}\text { Power System } \\
\text { Transient }\end{array}$ & $\begin{array}{l}\text { Power System } \\
\text { Harmonics }\end{array}$ & $\begin{array}{l}\text { Electrostatic } \\
\text { Discharge }\end{array}$ & Power Factor \\
\hline $\begin{array}{l}\text { - Low Freq } \\
\text { phenomena } \\
\text { - Produce Voltage } \\
\text { sag / swell }\end{array}$ & $\begin{array}{l}\text { - High freq } \\
\text { phenomena } \\
\text { - interaction } \\
\text { between electric } \\
\text { and magnetic } \\
\text { field }\end{array}$ & $\begin{array}{l}\text { - Fast, short- } \\
\text { duration event } \\
\text { - Produce } \\
\text { distortion like } \\
\text { notch, impulse }\end{array}$ & $\begin{array}{l}\text { - Low frequency } \\
\text { phenomena } \\
\text { - Produce } \\
\text { waveform } \\
\text { distortion }\end{array}$ & $\begin{array}{l}\text { - Current flow } \\
\text { with different } \\
\text { potentials } \\
\text { - Caused by direct } \\
\text { current or } \\
\text { induced } \\
\text { electrostatic field }\end{array}$ & $\begin{array}{l}\text { Low power } \\
\text { factor causes } \\
\text { equipment } \\
\text { damage }\end{array}$ \\
\hline
\end{tabular}

\section{Grid integration of Renewable Energy Systems - Power Quality Issues}

\section{A Solar Photovoltaic Systems:}

Though the output of a PV panel depends on the solar intensity and cloud cover, the PQ problems not only depend on irradiation but also are based on the overall performance of solar photovoltaic system including PV modules, inverter, filters controlling mechanism etc. Studies presented in [7], show that the short fluctuation of irradiance and cloud cover play an important role for low-voltage distribution grids with high penetration of PV. Therefore, special attention should be paid to the voltage profile and the power flow on the line. It also suggests that voltage and power mitigation can be achieved using super-capacitors which result in an increase of about $20 \%$ in the cost of the PV system. Voltage swell may also occur when heavy load is removed from the connection. Concerning DG, voltage disturbance can cause the disconnection of inverters from the grid and therefore result in losses of energy (Fig.1). Also long term performance of grid connected PV systems shows a remarkable degradation of efficiency due to the variation of source and performance of inverter [8].

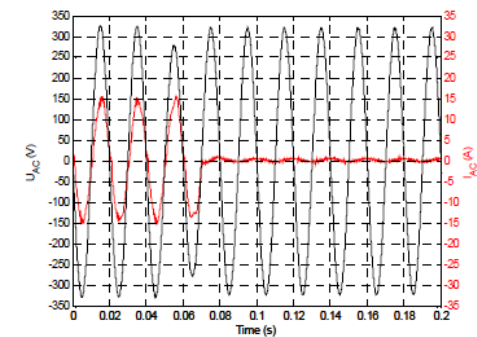

Fig. 1. Behaviour of a very sensitive inverter (fast disconnection for a short and shallow voltage sag) [9]

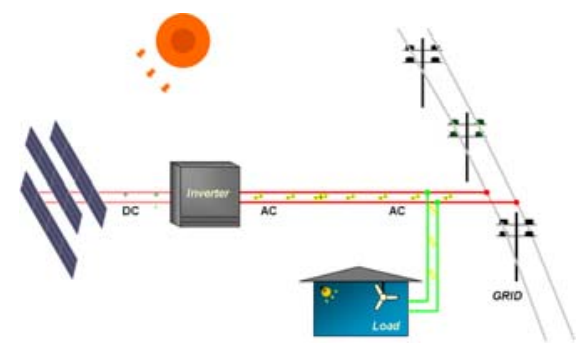

Fig. 2. General structure of grid-connected PV system

The general block diagram of grid connected PV system is shown in Fig 2 and the system can be a single-phase or three phase depending on the grid connection requirements. The PV array can be a single or a string of
PV panels either in series or parallel mode connection. Centralized or decentralized mode of PV systems can also be used and the overview of these PV-Inverter-Grid connection topologies along with their advantages and disadvantages are discussed in [10].

These power electronics converters, together with the operation of non-linear appliances, inject harmonics to the grid. In addition to the voltage fluctuation due to irradiation, cloud cover or shading effects could make the PV system unstable in terms of grid connection. Therefore, this needs to be considered in the controller design for the inverter [11-12].

In general, a grid-connected PV inverter is not able to control the reactive and harmonic currents drawn from non-linear loads. An interesting controlling mechanism has been presented in [13] where a PV system is used as an active filter to compensate the reactive and harmonic current as well as injecting power to the grid. This system can also operate in stand-alone mode. But the overall control circuit becomes somewhat more complex. Research [14] also shows that remarkable achievements have been made on improving inverter control to provide the reactive power compensation and harmonic suppression as ancillary services. A multifunctional PV Inverter for a grid connected system (Fig 3) has been developed recently and presented in [15]. This system demonstrates the reliability improvement through UPS functionality, harmonic compensation, reactive power compensation capability together with the connection capability during the voltage sag condition. However, the results show that the PQ improvement remains out of the IEEE range.

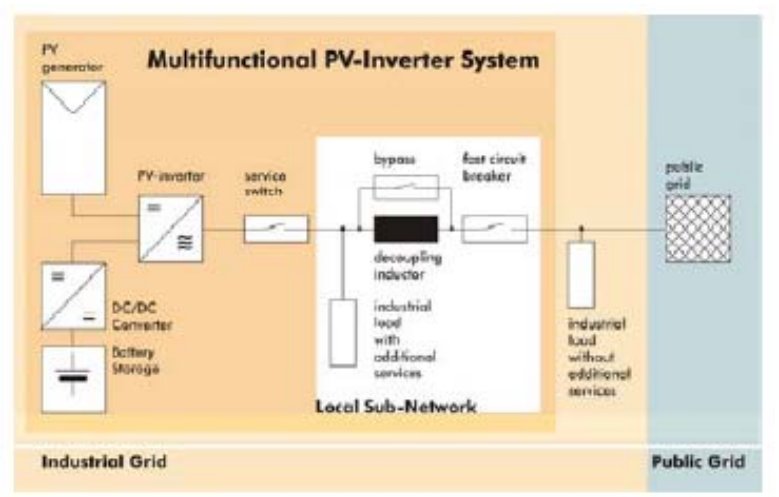

Fig. 3. Concept of a Multifunctional PV-Inverter System integrated into an industrial grid [15]

B. Wind Energy System: 
A simplified diagram representing some of the common types of wind energy systems are shown in Fig 4. From the design perspective it is found that some generators are directly connected to the grid through a dedicated transformer while others incorporate power electronics. Many designs, however, include some level of power electronics to improve controllability and operating range. Whatever connection configuration is used, each turbine itself has an effect on the power quality of the transmission system. Recent analysis and study [16] shows that the impact of the yaw error and horizontal wind shear on the power (torque) and voltage oscillations is more severe than the effects due to the tower shadow and vertical wind shear.

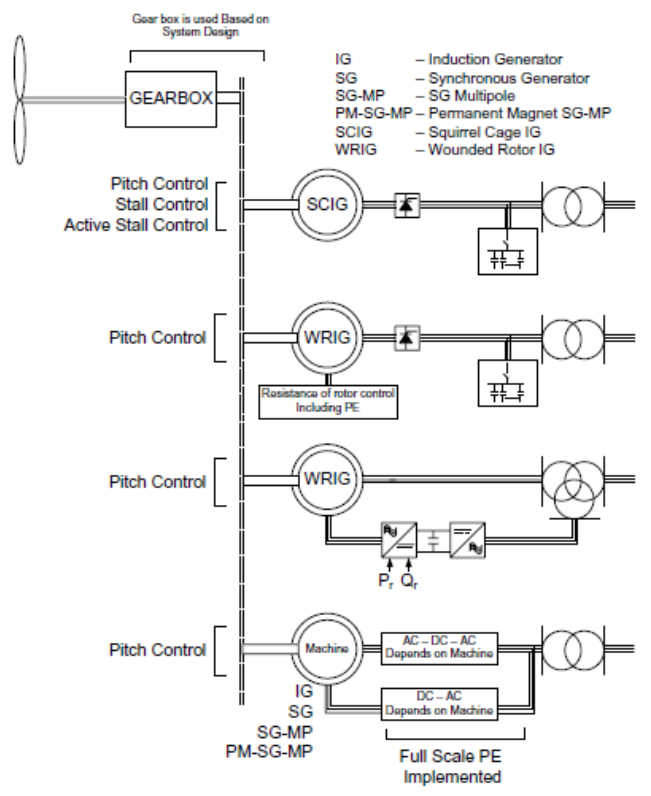

Fig. 4. Different types of wind energy system

A literature survey [17] of the new grid codes adopted for wind power integration has identified the problems of integrating large amounts of wind energy to the electric grid. It suggests that new wind farms must be able to provide voltage and reactive power control, frequency control and fault ride-through capability in order to maintain the electric system stability. For the existing wind farms with variable speed, double-fed induction generators (DFIG) and synchronous generators (SG), a frequency response in the turbine control system can be incorporated by a software upgrade. Wind farms with fixed speed induction generators (FSIG) have to be phased out because they cannot offer the required voltage or frequency control. An overview of the developed controllers for the converter of grid connected system has also been discussed in [18] and showed that the DFIG has now the most efficient design for the regulation of reactive power and the adjustment of angular velocity to maximize the output power efficiency. These generators can also support the system during voltage sags. However, the drawbacks of converter-based systems are harmonic distortions injected into the system. Being a single-stage buck-boost inverter, the recently proposed Zsource inverter (ZSI) can be a good candidate to mitigate the PQ problems for future DG systems connected to the grid [19] (Fig 5).

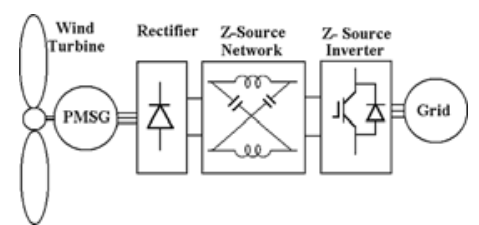

Fig. 5. PMSG-based WECS with dc boost chopper and ZSI [19]

Anti-islanding is one of the important issues for grid connected DG system. A major challenge for the islanding operation and control schemes is the protection coordination of distribution systems with bidirectional flows of fault current. This is unlike the conventional over-current protection for radial systems with unidirectional flow of fault current. Therefore extensive research in being carried out and an overview of the existing protection techniques with islanding operation and control, for preventing disconnection of DGs during loss of grid, has been discussed in [20].

\section{Impact of Power Quality Problems}

The impacts of power quality are usually divided into three broad categories: direct, indirect and social. A detail of these impacts has been described in [21].

A recent survey based on interviews and web based submission, conducted over a 2-year period in 8 European countries, has been reported in [22]. Survey reported PQ costs due to the effect of voltage dips and swells, short interruptions, long interruptions, harmonics, surges and transients, flicker, unbalance, earthing and electromagnetic compatibility (EMC) problems. It is found that the annual cost of wastage caused by poor PQ for EU-25 according to this analysis exceeds $€ 150 \mathrm{bn}$ where industry accounts for over $90 \%$ of this wastage. Dips and short interruptions account for almost $60 \%$ of the overall cost to industry and $57 \%$ for the total sample. The study also shows that the economic impact of inadequate PQ costs industry and service sector some 4\% and $0.15 \%$ of their annual turnover. Fig 6 shows the PQ costs for the EU-25 countries by sector. At the same time it is necessary to consider the impact of DG in terms of the cost of power quality. In [23], a method to evaluate the dip and interruption costs due to DG into the grid has been proposed. Based on the operating hours, the frequencies of $\mathrm{PQ}$ events occur and cost of $\mathrm{PQ}$ events indicates the positive or negative impact of DG.

\section{Mitigation of PQ problems}

There are two ways to mitigate the power quality problems - either from the customer side or from the utility side. The first approach is called load conditioning, which ensures that the equipment is less sensitive to power disturbances, allowing the operation even under significant voltage distortion. The other solution is to install line conditioning systems that suppress or counteracts the power system disturbances. Several devices including flywheels, super-capacitors, other energy storage systems, constant voltage transformers, noise filters, isolation transformers, transient voltage 
surge suppressors, harmonic filters are used for the mitigation of specific PQ problems. Custom power devices (CPD) like DSTATCOM, DVR and UPQC are capable of mitigating multiple PQ problems associated with utility distribution and the end user appliances. The following section of the paper looks at the role of CPDs in mitigating $\mathrm{PQ}$ problems in relation to grid integrated solar and wind energy systems.

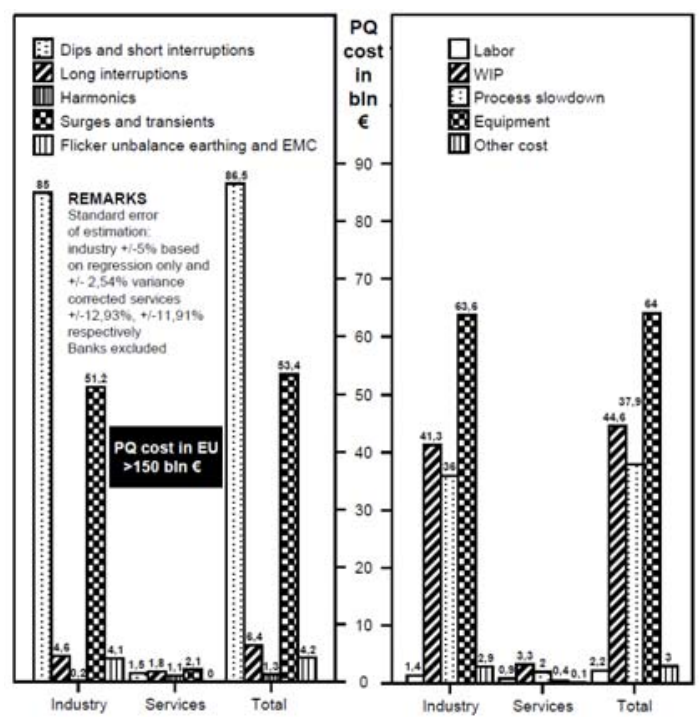

Fig. 6. Extrapolation of PQ cost to EU economy in LPQI surveyed sectors [22]

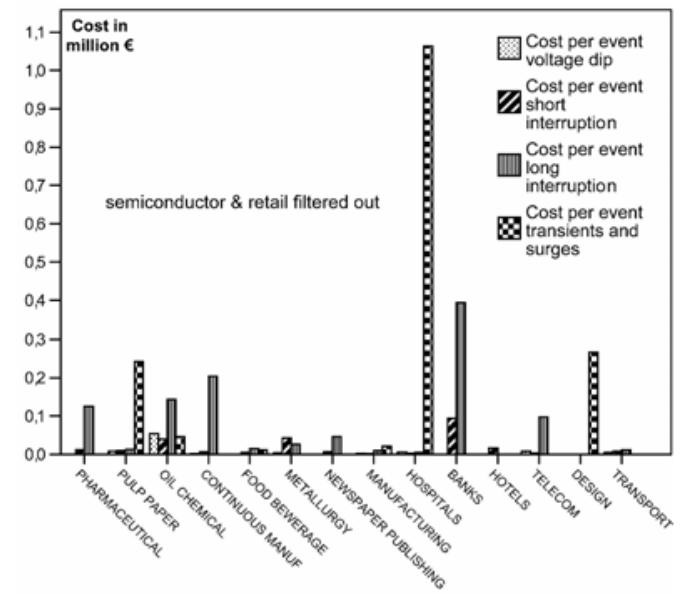

Fig. 7. The cost per event identified by the Survey [22]

\section{Role of Custom Power Devices}

The Custom Power (CP) concept was first introduced by N.G. Hingorani in 1995 [24]. Custom Power embraces a family of power electronic devices, or a toolbox, which is applicable to distribution systems to provide power quality solutions. This technology has been made possible due to the widespread availability of cost effective high power semiconductor devices such as GTOs and IGBTs, low cost microprocessors or microcontrollers and techniques developed in the area of power electronics.

DSTATCOM is a shunt-connected custom power device specially designed for power factor correction, current harmonics filtering, and load balancing. It can also be used for voltage regulation at a distribution bus [25]. It is often referred to as a shunt or parallel active power filter. It consists of a voltage or a current source PWM converter (Fig. 8). It operates as a current controlled voltage source and compensates current harmonics by injecting the harmonic components generated by the load but phase shifted by 180 degrees. With an appropriate control scheme, the DSTATCOM can also compensate for poor load power factor.

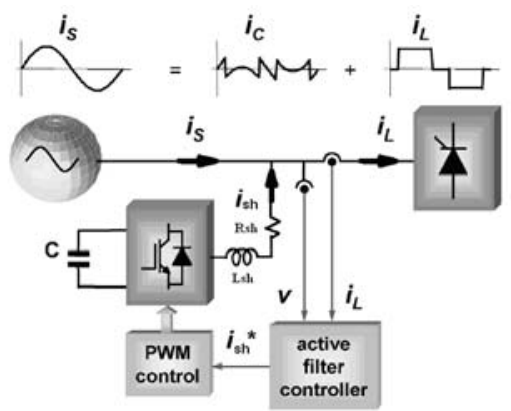

Fig. 8. System configuration of DSTATCOM

The DVR is a series-connected custom power device to protect sensitive loads from supply side disturbances (except outages). It can also act as a series active filter, isolating the source from harmonics generated by loads. It consists of a voltage-source PWM converter equipped with a dc capacitor and connected in series with the utility supply voltage through a low pass filter (LPF) and a coupling transformer [26] as shown in Fig 9. This device injects a set of controllable ac voltages in series and in synchronism with the distribution feeder voltages such that the load-side voltage is restored to the desired amplitude and waveform even when the source voltage is unbalanced or distorted.

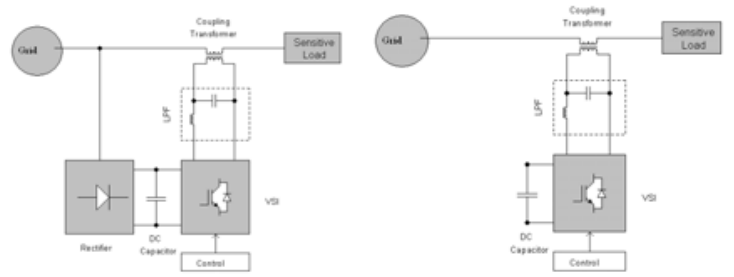

Fig 9 (a): Rectifier supported (b) DC capacitor supported DVR

UPQC is the integration of series and shunt active filters, connected back-to-back on the dc side and share a common DC capacitor [27] as shown in Fig 10. The series component of the UPQC is responsible for mitigation of the supply side disturbances: voltage sags/swells, flicker, voltage unbalance and harmonics. It inserts voltages so as to maintain the load voltages at a desired level; balanced and distortion free. The shunt component is responsible for mitigating the current quality problems caused by the consumer: poor power factor, load harmonic currents, load unbalance etc. It injects currents in the ac system such that the source currents become balanced sinusoids and in phase with the source voltages.

The application of the STATCOM is already reported for wind power applications in stability enhancement, transient, flicker mitigation etc. [28-29]. As the traditional STATCOM works only in leading and lagging 
operating mode, its application is therefore limited to reactive power support only. The fluctuating power due to the variation of wind cannot be smoothed by using a STATCOM, because it has no active power control ability. To overcome this problem, Battery Energy Storage System (BESS) has been incorporated with STATCOM (STATCOM/BESS) [30], which has both real and reactive power control ability (Fig 11).

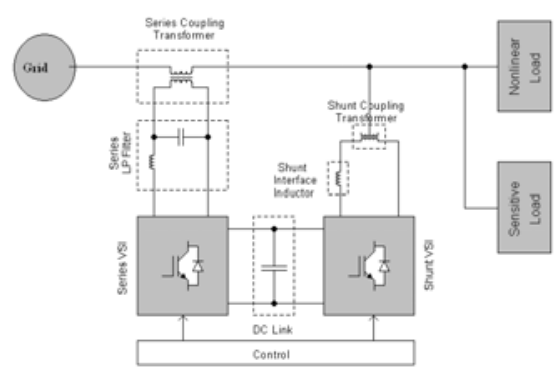

Fig. 10: System configuration of UPQC

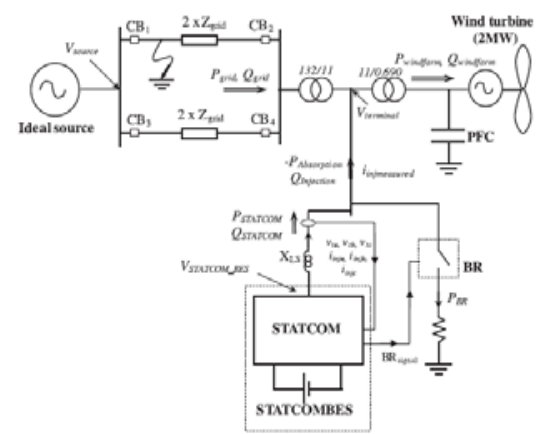

Fig. 11. STATCOM BES and BR to improve power quality and stability of wind farm [30]

Similarly the DVR can also be used with BESS to control the reactive and active power flow with harmonic voltage mitigation for a grid-connected, distributed generation system [31], Fig 12.

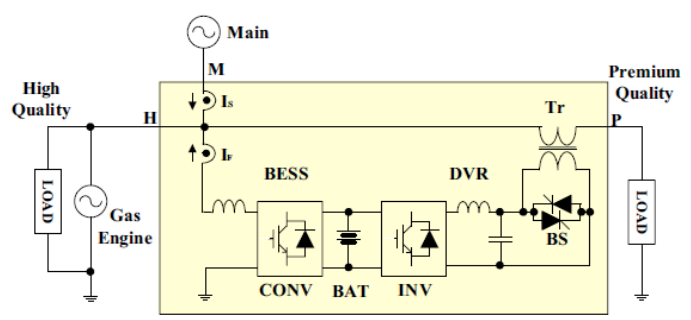

Fig. 12. Power quality control using DVR and BESS [31]

Very recent research reports [32,33] show that significant research and development has been carried out on the application of UPQC to grid-connected PV and wind energy systems. As the UPQC can compensate for almost all existing $\mathrm{PQ}$ problems in the transmission and distribution grid, placement of a UPQC in the distributed generation network can be multipurpose.

A structure has been proposed in [32] (see Fig. 13), where PV is connected to the DC link in the UPQC as an energy source. It works both in interconnected and islanded mode. UPQC has the ability to inject power using $\mathrm{PV}$ to sensitive loads during source voltage interruption. The advantage of this system is voltage interruption compensation and active power injection to the grid in addition to the other normal UPQC abilities. But the system's functionality may be compromised if the solar resource is not sufficient during the voltage interruption condition.

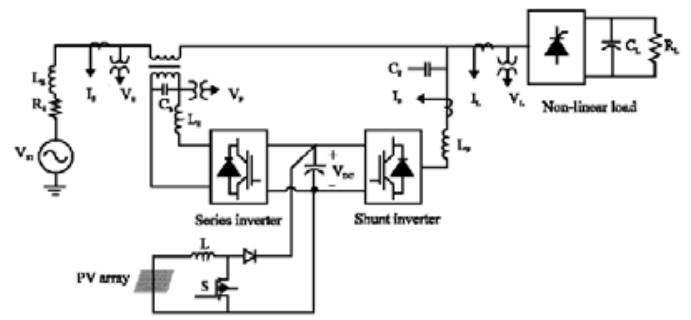

Fig. 13. UPQC with grid connected PV [32]

The application of a UPQC to overcome the grid integration problems of the FSIG is investigated in [33], (see Fig 14) .The FSIG fails to remain connected to the grid in the event of grid voltage dip or line fault due to excessive reactive power requirement The drop in voltage creates overspeeding of turbine, which causes a protection trip. With the aid of the UPQC, this fault-ridethrough capability is achieved, which greatly enhances system stability. Result show that the UPQC as one of the best devices for the integration of wind energy system to the grid

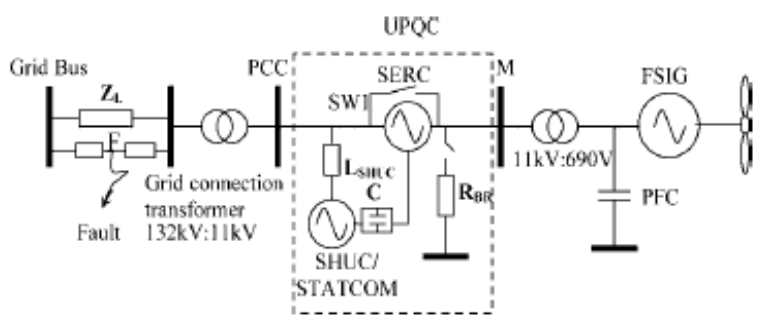

Fig. 14. Grid connected wind energy system with UPQC [33]

The concept of a custom power park has been proposed in [34 - 35] using CPDs, to provide quality power at various level. It has been extended further ([36], see Fig 15) by using supervisory control techniques to coordinate the custom power devices by proving the pre-specified quality of power.

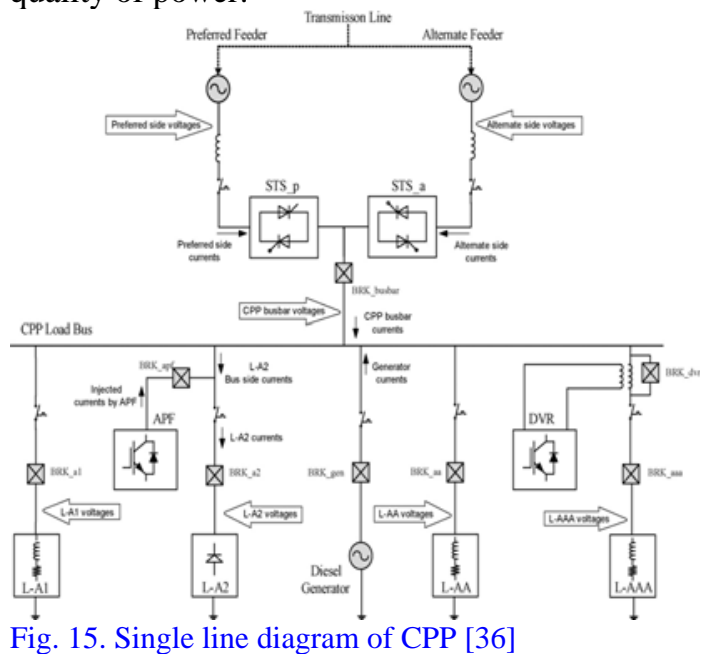

7. Conclusion

Recent trends in the power generation and distribution system shows that penetration level of DG into the grid 
has increased considerably. End user appliances are becoming more sensitive to the power quality condition. Extensive research on CPDs for the mitigation of $\mathrm{PQ}$ problems are also carried out. CPDs are found to be very capable in integrating solar and wind energy sources to the grid. They play an important role in the concept of custom power park in delivering quality power at various levels.

\section{References}

[1] I. El-Samahy, El-Saadany, "The Effect of DG on Power Quality in a Deregulated Environment," in IEEE Power Engineering Society General Meeting 2005, pp.2969-2976. [2] S.M Halpin, L.L. Grigsby The Electric Power Engineering Handbook, CRC Press LLC (2001), pp 15.4

[3] C. Sankaran, Power Quality, CRC Press (2002), pp. 12-13

[4] R D. Henderson, P J. Rose, "Harmonics: The Effects On Power Quality And Transformers”, IEEE Trans Industry Appl, 1994, Vol 30(3), pp 528 - 532

[5] S.M Halpin, L.L. Grigsby The Electric Power Engineering Handbook, CRC Press LLC (2001), pp 15.22-23

[6] IEEE 1547, IEEE Standard for Interconnecting Distributed Resources with Electric Power Systems, 2003, pp. 8-10

[7] G Chicco, J Schlabbach, F Spertino, "Experimental assessment of the waveform distortion in grid-connected photovoltaic installations”, Solar Energy, 2009, vol. 83, pp 1026-1039

[8] J D Mondol, Y Yohanis, M Smyth, B Norton, "Long term performance analysis of a grid connected photovoltaic system in Northern Ireland”, Energy Conv \& Mang, 2006, vol. 47, pp. 2925-2947

[9] H Fechner, R Bründlinger, B Bletterie, Power quality and safety aspects for grid connection of Photovoltaic Systems, 2005,http://www.arsenal.ac.at/downloads/Publikationen/2005/P ower Quality and Safety Aspects.pdf

[10] F. Blaabjerg, Z. Chen, S.B. Kjaer, "Power Electronics as Efficient Interface in Dispersed Power Generation Systems", IEEE Trans. on PE, 2004, Vol. 19(4), pp 184 - 1194

[11] R Teodorescu, F Blaabjerg M Liserre, U Borup, “A New Control Structure for Grid-Connected PV Inverters with Zero Steady- State Error and Selective Harmonic Compensation" in Proc. PESC2004, pp 1742 - 1747

[12] X. Yuan, W. Merk, H. Stemmler, J. Allmeling, “Stationary Frame Generalized Integrators for Current Control of Active Power Filters with Zero Steady-State Error for Current Harmonics of Concern Under Unbalanced and Distorted Operating Conditions” IEEE Trans. on Ind. App., 2002, vol. 38(2), pp.523 - 532

[13] H Calleja, H Jimenez, "Performance of a grid connected PV system used as active filter”, Energy Conv \& Mang, 2004, vol. 45, pp 2417-2428

[14] Prodanovic, K D Brabandere, et al., "Harmonic and reactive power compensation as ancillary services in inverter based distributed generation”, Generation, Transmission \& Distribution, IET 2007, vol. 1(3), pp 432-438

[15] Geibel, D., T. Degner, "Improvement of Power Quality and Reliability with multifunctional PV-inverters in distributed energy systems", in EPQU2009.

[16] R Fadaeinedjad, G Moschopoulos, M Moallem "The Impact of Tower Shadow, Yaw Error, and Wind Shears on Power Quality in a Wind-Diesel System”, IEEE Trans Energy Conversion, 2009, Vol. 24 (1), pp $102-111$

[17] I M de Alegria, J Andreu, J L Martın, P Ibanez, J L Villate, $\mathrm{H}$ Camblong, "Connection requirements for wind farms: A survey on technical requierements and regulation”, Renewable and Sustainable Energy Reviews, 2007, vol. 11, 1858-1872 [18] F Blaabjerg, R Teodorescu, M Liserre, A V. Timbus, "Overview of Control and Grid Synchronization for Distributed
Power Generation Systems”, IEEE Trns Indust Elect, 2006 , Vol. 53(5), pp 1398 - 1409

[19] S M Dehghan, M Mohamadian and A Y Varjani, “A New Variable-Speed Wind Energy Conversion System Using Permanent Magnet Synchronous Generator and Z-Source Inverter”, IEEE Trns Energy Conv, 2009, Vol 24(3), 714 - 724 [20] S.P. Chowdhurya, S. Chowdhurya, P.A. Crossleyb, "Islanding protection of active distribution networks with renewable distributed generators: A comprehensive survey”, Electric Power Systems Research, 2009, vol 79, pp. 984-992 [21] A Baggini, Handbook of Power Quality, John Wiley \& Sons Ltd, UK(2008), pp. 545 - 546

[22] J Manson, R Targosz, "European Power Quality Survey Report”, 2008, pp. 3 - 15

[23] L Yufeng, "Evaluation of dip and interruption costs for a distribution system with distributed generations”, ICHQP2008. [24] N.G. Hingorani, "Introducing custom power", IEEE Spectrum, 1995, vol. 32(6), pp. 41-48.

[25] A Ghosh and G Ledwich, Power quality enhancement using custom power devices, Kluwer Academic, 2002

[26] A Ghosh, "Compensation of Distribution System Voltage Using DVR”, IEEE Trans on power delivery, 2002, vol. 17(4), pp. 1030 - 1036

[27] H Fujita, H Akagi, “The Unified Power Quality

Conditioner: The Integration of Series- and Shunt-Active

Filters”, IEEE Trns on power electronics, 1998, vol. 13, no. 2, pp.315-322.

[28] A Arulampalam, M. Barnes, "Power quality and stability improvement of a wind farm using STATCOM supported with hybrid battery energy storage." Generation, Transmission and Distribution, IEE Proceedings, 2006, vol. 153(6): 701-710 [29] Z. Chen, F. Blaabjerg, Y. Hu, "Voltage recovery of dynamic slip control wind turbines with a STATCOM”, IPEC05, vol. S29(5), pp. 1093-1100.

[30] S.M. Muyeen, R Takahashi, T Murata, J Tamura, M H Ali, "Application of STATCOM/BESS for wind power smoothening and hydrogen generation”, Electric Power Systems Research, 2009, vol. 79, pp 365-373

[31] Chung, Y. H., H. J. Kim, "Power quality control center for the microgri system", PECon 2008

[32] M Hosseinpour, Y Mohamadrezapour, S Torabzade,

"Combined operation of Unifier Power Quality Conditioner and Photovoltaic Array”, Journal of Applied Sciences, 2009, v-9(4), pp 680-688

[33] Jayanti, N. G., M. Basu, "Rating requirements of the unified power quality conditioner to integrate the fixed speed induction generator-type wind generation to the grid." Renewable Power Generation, IET, 2009, vol. 3(2): 133-143. [34] A. Domijan, A. Montenegro, "Simulation study of the world's first distributed premium power quality park”, IEEE Trans on Power Delivery, 2005, vol. 20, pp 1483-1492. [35] A. Ghosh, A. Joshi, "The concept and operating principles of a mini custom power park", IEEE Trns on Power Delivery, 2004, vol. 4, pp 1766-1774.

[36] M. E Meral, A Teke, K. C Bayindir, M Tumay, "Power quality improvement with an extended custom power park”, Electric Power Systems Research, 2009, vol. 79, pp 1553-1560 